\title{
Review Article \\ Targeting Hepatic Glycerolipid Synthesis and Turnover to Treat Fatty Liver Disease
}

\author{
George G. Schweitzer and Brian N. Finck \\ Washington University School of Medicine, St. Louis, MO 63110, USA \\ Correspondence should be addressed to Brian N. Finck; bfinck@dom.wustl.edu \\ Received 5 January 2014; Accepted 3 March 2014; Published 10 April 2014 \\ Academic Editor: Stefano Bellentani
}

Copyright ( 2014 G. G. Schweitzer and B. N. Finck. This is an open access article distributed under the Creative Commons Attribution License, which permits unrestricted use, distribution, and reproduction in any medium, provided the original work is properly cited.

\begin{abstract}
Nonalcoholic fatty liver disease (NAFLD) encompasses a spectrum of metabolic abnormalities ranging from simple hepatic steatosis (accumulation of neutral lipid) to development of steatotic lesions, steatohepatitis, and cirrhosis. NAFLD is extremely prevalent in obese individuals and with the epidemic of obesity; nonalcoholic steatohepatitis (NASH) has become the most common cause of liver disease in the developed world. NASH is rapidly emerging as a prominent cause of liver failure and transplantation. Moreover, hepatic steatosis is tightly linked to risk of developing insulin resistance, diabetes, and cardiovascular disease. Abnormalities in hepatic lipid metabolism are part and parcel of the development of NAFLD and human genetic studies and work conducted in experimentally tractable systems have identified a number of enzymes involved in fat synthesis and degradation that are linked to NAFLD susceptibility as well as progression to NASH. The goal of this review is to summarize the current state of our knowledge on these pathways and focus on how they contribute to etiology of NAFLD and related metabolic diseases.
\end{abstract}

\section{Introduction}

Overwhelming evidence links obesity with increased risk for several chronic diseases including insulin resistance, diabetes mellitus, dyslipidemias, and nonalcoholic fatty liver disease (NAFLD). The condition, NAFLD, encompasses both hepatic steatosis (the accumulation of neutral lipid within the cytosol of hepatocytes) and the more severe nonalcoholic steatohepatitis (NASH; hepatic inflammation and fibrosis associated with steatotic lesions). With the epidemic of obesity in the USA, the occurrence of NAFLD has risen exuberantly, becoming the most common cause of liver disease $[1,2]$. It is now estimated that $14-24 \%$ of the general population and up to $80 \%$ of morbidly obese subjects have contracted NAFLD [3-6].

Although hepatic steatosis is extremely prevalent, only a subset of afflicted individuals experience severe liver damage and progress to cirrhosis. Hepatic steatosis promotes an inflammatory state including augmented production of reactive oxygen species (ROS) and proinflammatory cytokines. This "second hit" is believed to be required to drive the transition from simple steatosis to steatohepatitis $[5,7-9]$.
Although the exact cause of the inflammation is difficult to pinpoint, hepatic steatosis is linked to heightened production of ROS [7, 10-13], which are known to cause mitochondrial damage. Mitochondrial injury further exacerbates ROS production, diminishes the capacity to oxidize excess fatty acids, and is also linked to apoptotic death [11]. A vicious feedforward cycle involving mitochondrial impairment and ROS production is thought to induce hepatocyte necrosis and apoptosis and drive the progression from steatosis to NASH.

\section{Perturbed Lipid Homeostasis in Obesity and Its Role in the Pathogenesis of NAFLD}

The pathogenic mechanisms linking obesity to NAFLD and the sources of the fat that accumulate in the liver are likely manifold. Susceptibility is also strongly influenced by both genetic and environmental factors. Consuming diets rich in fat or simple sugars can certainly be linked to development of NAFLD in a variety of murine systems. Adipose tissue insulin resistance, which is common in obese individuals, may also contribute because insulin normally suppresses 


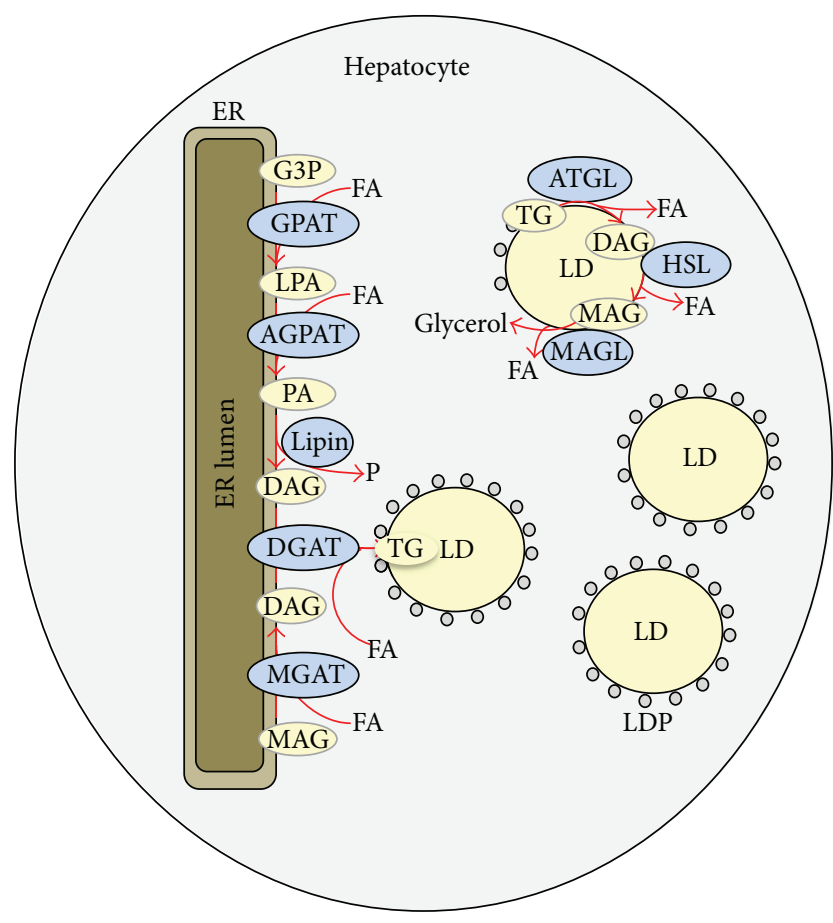

FIGURE 1: The pathways for triglyceride synthesis and hydrolysis are shown. Fatty acid (FA), phosphate (P), glycerol-3-phosphate (G-3-P), G-3-P acyltransferase (GPAT), lysophosphatidic acid (LPA), acylglycerol-3-phosphate acyltransferase (AGPAT), phosphatidic acid (PA), monoacylglycerol (MAG), MAG acyltransferase (MGAT), diacylglycerol (DAG), DAG acyltransferase (DGAT), triglyceride (TG), lipid droplet (LD), LD protein (LDP), adipose tissue triglyceride lipase (ATGL), hormone sensitive lipase (HSL), MAG lipase (MAGL), and endoplasmic reticulum (ER).

adipose tissue lipolysis and, when insulin signaling is defective, lipolytic rates in adipose tissue increase [14-17]. High levels of free fatty acids are released into circulation and accrete in tissues not normally involved in fatty acid storage, including the liver. Despite evidence that rates of fatty acid oxidation and very low density lipoprotein secretion are increased in obese individuals $[18,19]$, the chronic oversupply of fatty acids outstrips the capacity of liver to deal with these lipids, leading to fat accumulation within the cytosol of hepatocytes. Moreover, hepatic lipid accumulation leads to insulin resistance, which further exacerbates fatty acid oversupply by increasing de novo hepatic lipogenesis [20].

Triglyceride (triacylglycerol) is the primary storage form of intracellular lipid and this glycerolipid is solely generated from acylation of DAG. As indicated by its name, triacylglycerol is composed of three acyl chains (fatty acids) esterified to a glycerol backbone. In most cells of the body, triglyceride is produced primarily from the sequential acylation and dephosphorylation of glycerol-3-phosphate in the endoplasmic reticulum membrane (Figure 1) [21, 22]. However, recent evidence from other types of cells has suggested that enzymes involved in this pathway may also be localized to nascent lipid droplets to cause the enlargement of the lipid droplets via progressive lipidation [23]. It is not known whether this also occurs in hepatocytes. Glycerol-3-phosphate acyltransferase (GPAT) enzymes catalyze the addition of the first fatty acid to form lysophosphatidic acid (LPA). Acylglycerol-3-phosphate acyltransferase (AGPAT) or LPA acyltransferase (LPAAT) enzymes acylate LPA to form phosphatidic acid (PA), which is the substrate for the PA phosphohydrolase (PAP) enzymes commonly known as lipin proteins. The removal of the phosphate group from PA by lipins generates diacylglycerol (DAG) that is acylated by DAG acyltransferase (DGAT) enzymes to form triglyceride. Whereas dephosphorylation of PA is the principal pathway for generating DAG in most cell types, there are also alternative pathways for synthesizing DAG, including acylation of monoacylglycerol (MAG), which is catalyzed by monoacylglycerol acyltransferase (MGAT) enzymes (Figure 1). The importance of the ability to store triglyceride for survival of the organism is evidenced by the existence of multiple isoforms of enzymes with functional redundancy for each step in the triglyceride synthesis pathway in higher organisms. While this is adaptive for organismal survival, it greatly complicates our ability to tease apart the role that each enzyme plays in intermediary metabolism and dysregulation of these pathways in disease states likely contributes to the pathology of the disease (Table 1).

Triglycerides and other complex glycerolipids are hydrophobic and to store these lipids in the aqueous cytosol, they are packaged and stored in lipid droplets (LD). Unlike adipocytes, which usually contain one large unilocular LD, hepatic steatosis is often characterized by accumulation of multiple LD in the cytosol. Hepatic steatosis can also be categorized as macrovesicular steatosis, where the accumulated lipid displaces and distorts the nucleus, or microvesicular steatosis. Macrovesicular steatosis is usually associated with chronic or advanced stages of fatty liver disease including steatohepatitis, fibrosis, and cirrhosis $[24,25]$, whereas microvesicular disease is often secondary to mitochondrial dysfunction [26-28] or in acute forms of hepatic steatosis [29]. However, the mechanisms driving these two patterns of lipid accumulation are not known. Lipid droplets are composed of a triglyceride-rich core with a phospholipid coat. A number of proteins also coat the surface of the lipid droplet to buffer the LD, regulate lipolysis, and modulate LD trafficking. The most well-known classes of lipid droplet proteins (LDP) are the perilipin family (perilipin 1, 2, 3, 4, and 5 proteins) and the cell death-inducing DFFA-like effector family (CIDEA, CIDEB, and CIDEC). As discussed further below, loss of these proteins blunts the ability of the cell to efficiently store lipid, suggesting that this coating of the lipid droplet is required for cytosolic storage.

Steady state lipid levels are highly influenced by rates of hydrolysis. The principal triglyceride lipase is known as the adipose tissue triglyceride lipase (ATGL). Hormone sensitive lipase (HSL), once considered the primary triglyceride lipase, is now known to act primarily as a DAG lipase. It should also be noted that a number of phospholipases and other categories of lipases and hydrolases may also play a role in lipid turnover and disposal. For example, patatin-like phospholipase domain containing 3 (PNPLA3) is a lipase with sequence similarity to ATGL and genetic variation in the 
TABLE 1: Effects of modulating expression of triglyceride metabolism enzymes on hepatic steatosis and insulin sensitivity.

\begin{tabular}{|c|c|c|c|c|}
\hline Protein & Function & Normal chow diet & High fat diet & $\mathrm{ob} / \mathrm{ob}$ \\
\hline \multirow{2}{*}{ GPAT1 } & GOF & $\uparrow H S^{v} \downarrow I S^{v}[36]$ & & \\
\hline & LOF & $\downarrow H S^{g} \uparrow S^{g}[37-39]$ & $\downarrow H S^{g} \uparrow I^{g}[37-39]$ & $\downarrow H S^{\mathrm{g}} \leftrightarrow \mathrm{IS}^{\mathrm{g}}[40]$ \\
\hline GPAT4 & LOF & $\downarrow H S^{g}[44]$ & $\downarrow H S^{\mathrm{g}}[44]$ & \\
\hline AGPAT2 & LOF & $\uparrow H S^{g}[47]$ & & \\
\hline \multirow{3}{*}{ Lipin 1} & GOF & $\uparrow \mathrm{HS}^{\mathrm{v}}[51]$ & & $\uparrow \mathrm{IS}^{\mathrm{v}}[56]^{*}$ \\
\hline & LOF & $\uparrow \mathrm{HS}^{\mathrm{g}} \downarrow \mathrm{IS}^{\mathrm{g}}[143,144]$ & & \\
\hline & LS-LOF & $\leftrightarrow \mathrm{HS}^{\mathrm{g}}[55]$ & $\downarrow H S^{\mathrm{r}} \uparrow \mathrm{IS}^{\mathrm{r}}[62]$ & \\
\hline \multirow{3}{*}{ Lipin 2} & GOF & $\leftrightarrow \mathrm{HS}^{\mathrm{v}} \leftrightarrow \mathrm{IS}^{\mathrm{v}}[66]$ & $\uparrow H S^{v} \downarrow I^{v}[66]$ & \\
\hline & LOF & $\leftrightarrow H S^{r} \leftrightarrow I S^{r}[66]$ & & \\
\hline & LS-LOF & & $\downarrow H S^{r} \uparrow I S^{r}[66]$ & \\
\hline Lipin 3 & LOF & $\downarrow H S^{g}[145]$ & & \\
\hline MOGAT1 & LS-LOF & & $\downarrow H S^{\mathrm{g}} \uparrow \mathrm{IS}^{\mathrm{r}, \mathrm{a}}[71,72]$ & $\downarrow H S^{\mathrm{a}} \uparrow \mathrm{IS}^{\mathrm{a}}[72]$ \\
\hline MOGAT2 & LOF & & $\downarrow H S^{g} \uparrow I^{g}[73]$ & \\
\hline \multirow{3}{*}{ DGAT1 } & LOF & $\leftrightarrow \mathrm{HS}^{\mathrm{g}} \uparrow \mathrm{IS}^{\mathrm{g}}[75,76]$ & $\downarrow H S^{g} \uparrow \mathrm{IS}^{\mathrm{g}}[76,77]$ & $\leftrightarrow \mathrm{HS}^{\mathrm{a}}[79]$ \\
\hline & & & $\downarrow \mathrm{HS}^{\mathrm{g}, \mathrm{a}}[76]$ & \\
\hline & LS-LOF & $\leftrightarrow \mathrm{HS}^{\mathrm{a}}[76]$ & $\leftrightarrow \mathrm{HS}^{\mathrm{a}} \leftrightarrow \mathrm{IS}^{\mathrm{a}}[78]$ & \\
\hline \multirow{3}{*}{ DGAT2 } & LOF & Lethal $^{\mathrm{g}}[82]$ & & \\
\hline & LS-LOF & $\downarrow H S^{\mathrm{a}} \uparrow \mathrm{IS}^{\mathrm{a}}[78]$ & $\downarrow H S^{\mathrm{a}} \uparrow \mathrm{IS}^{\mathrm{a}}$ rat $[78]$ & \\
\hline & & & $\downarrow \mathrm{HS}^{\mathrm{a}} \leftrightarrow \mathrm{IS}^{\mathrm{a}}$ mice $[83]$ & \\
\hline \multirow{3}{*}{$\begin{array}{l}\text { Perilipin } 2 \\
\text { (ADRP) }\end{array}$} & GOF & & & \\
\hline & LOF & $\downarrow \mathrm{HS}^{\mathrm{g}}[93,94]$ & $\downarrow H S^{\mathrm{g}}[94]$ & $\downarrow H S^{g} \uparrow S^{g}[95]$ \\
\hline & LS-LOF & & $\downarrow \mathrm{HS}^{\mathrm{a}} \uparrow \mathrm{IS}^{\mathrm{a}}[96,97]$ & \\
\hline Perilipin 5 & GOF & $\uparrow \mathrm{TG}^{\mathrm{v}}$ in cells [98] & & \\
\hline \multirow{2}{*}{ CIDEA } & LOF & $\leftrightarrow \mathrm{HS}^{\mathrm{g}}[100] \uparrow \mathrm{IS}^{\mathrm{g}}$ & $\downarrow H S^{g}[100] \uparrow I^{g}[103]^{\#}$ & $\downarrow H S^{g}[100]$ \\
\hline & LS-LOF & & & $\downarrow H S^{r}[100]$ \\
\hline CIDEB & LOF & $\leftrightarrow \mathrm{HS}^{\mathrm{g}} \uparrow \mathrm{IS}^{\mathrm{g}}[104]$ & $\downarrow \mathrm{HS}^{\mathrm{g}} \uparrow \mathrm{IS}^{\mathrm{g}}[104]$ & \\
\hline \multirow{2}{*}{$\begin{array}{l}\text { CIDEC } \\
\text { (Fsp27) }\end{array}$} & GOF & $\uparrow T G^{\mathrm{v}}$ in cells [110] & & $\uparrow H S^{v}[110]$ \\
\hline & LOF & & & $\downarrow H S^{r}[110]$ \\
\hline \multirow{4}{*}{ ATGL } & GOF & & & $\downarrow H S^{v}[116,120]$ \\
\hline & LOF & $\uparrow H S^{g, r} \leftrightarrow I^{g, r}[114,116,117]$ & & \\
\hline & LS-LOF & $\uparrow \mathrm{HS}^{\mathrm{g}}[115]$ & $\uparrow H S^{\mathrm{r}} \uparrow \mathrm{IS}^{\mathrm{g}, \mathrm{r}}[114,117]$ & \\
\hline & & & & \\
\hline \multirow{3}{*}{ HSL } & GOF & & & $\downarrow H S^{\mathrm{v}}[120]$ \\
\hline & LOF & $\uparrow H S^{\mathrm{g}}[123] \downarrow H S^{\mathrm{g}}[125,126]$ & $\uparrow H S^{g}[123] \downarrow H S^{g}[125,126]$ & \\
\hline & & $\leftrightarrow \mathrm{IS}^{\mathrm{g}}[125,126]$ & $\uparrow \mathrm{IS}^{\mathrm{g}}[125]$ & \\
\hline MAGL & LOF & $\uparrow I^{g}[127]$ & $\uparrow \mathrm{IS}^{\mathrm{g}}[127]$ & \\
\hline \multirow{3}{*}{ PNPLA3 } & LS-GOF ${ }^{\mathrm{I} 148}$ & $\leftrightarrow \mathrm{HS}^{\mathrm{oe}} \leftrightarrow \mathrm{IS}^{\mathrm{oe}}[141]$ & $\leftrightarrow \mathrm{HS}^{\mathrm{oe}}[141]$ & \\
\hline & LS-GOF ${ }^{\mathrm{I} 148 \mathrm{M}}$ & $\uparrow \mathrm{HS}^{\mathrm{g}} \leftrightarrow \mathrm{IS}^{\mathrm{g}}[141]$ & $\leftrightarrow \mathrm{HS}^{\mathrm{g}}[141]$ & \\
\hline & LOF & $\leftrightarrow \mathrm{HS}^{\mathrm{g}} \leftrightarrow \mathrm{IS}^{\mathrm{g}}[139]$ & $\leftrightarrow \mathrm{HS}^{\mathrm{g}} \leftrightarrow \mathrm{IS}^{\mathrm{g}}[139]$ & \\
\hline
\end{tabular}

HS: hepatic steatosis; IS: whole-body insulin sensitivity; GOF: gain of function (oe: transgenic overexpression; v: adenoviral overexpression); LOF: loss of function (g: gene knockout; r: RNAi-based disruption; a: ASO); LS-LOF: liver-specific loss of function; LS-GOF: liver-specific gain of function; ${ }^{*}$ UCP-DTA mice used. 
PNPLA3 gene is strongly associated with development of NAFLD and progression to NASH.

\section{Pathogenic Mechanisms Linking Hepatic Glycerolipid Metabolism and Chronic Disease}

Although triglyceride is the most abundant lipid storage form, this lipid is not commonly believed to be a pathogenic mediator of NAFLD. Triglyceride is relatively inert and is the preferred storage form of lipid. However, other intermediates in this pathway and complex lipids derived from these intermediates have been linked to liver inflammation, injury, and insulin resistance. For example, PA has been linked to impaired insulin signaling in hepatocytes via regulation of signaling cascades that feedback to inhibit insulin signaling pathways [30]. Similarly, DAG content has been associated with activation of protein kinase $\mathrm{C}$ isoforms that inhibit proximal insulin signaling components $[31,32]$. Ceramides and various sphingolipids can be derived from intermediates in the glycerolipid synthesis pathway and have been shown to have cytotoxic effects on cultured cells. Thus, there is abundant rationale for potentially targeting this pathway as a therapeutic approach once a comprehensive understanding of the pathogenic mediators has been gained.

Below, evidence for the roles that these enzymes and other related factors play in the pathogenesis of NAFLD will be discussed. One of the benefits of studying liver metabolism is the feasibility of overexpressing or knocking down the expression of genes by using adenoviral vectors or antisense oligonucleotides (ASO). This has allowed the field to selectively activate or suppress these factors in a liver-specific manner to test the effects on intermediary metabolism (Table 1). While it would seem straightforward that targeting the activity of these anabolic enzymes would attenuate or prevent hepatic steatosis, a number of surprising and conflicting outcomes in tractable model systems have revealed that modulating the activity of these enzymes does not always result in the predicted effects on the upstream or downstream lipids of these enzymes in liver.

\section{Pathways for Triglyceride Synthesis}

The work of Eugene Kennedy and others elucidated and characterized the enzymatic reactions that were required to convert glycerol-3-phosphate and three free fatty acids into triglyceride several decades ago. However, the cloning of the enzymes that catalyze these reactions is a much more recent development. The relatively recent identification of lipin proteins as PAP enzymes in 2006 [33] seems to have completed the process of identifying the enzymes responsible for these reactions. Although a number of other biosynthetic pathways are also tightly linked to triglyceride synthesis, for the purposes of this review, we will limit the discussion to enzymes in the committed pathways.

4.1. Glycerol-3-Phosphate Acyltransferase. The first committed step of converting glycerol-3-phosphate to triglyceride is its acylation by GPAT enzymes to form lysophosphatidic acid (LPA). As with many biological pathways, it is likely that this first step is rate-limiting for triglyceride synthesis in many contexts. Four GPAT family members (GPAT1, 2, $3,4)$ are found in higher organisms [34]. All GPATs are integral membrane proteins, but GPAT1 and GPAT2 are mitochondrial isoforms of the enzyme while GPAT3 and 4 are localized to the ER [34]. Our current knowledge suggests that GPAT1 and GPAT4 play important roles in hepatic glycerolipid synthesis. GPAT2 may not be highly involved in this process and GPAT3 is expressed only at low levels in that tissue.

Several studies have demonstrated via overexpression, knockdown, or knockout of GPAT1 that this GPAT family member is important for triglyceride synthesis. Overexpression of GPAT1 provokes a marked increase in cellular TG content in primary hepatocytes [35]. GPAT1 overexpression was also sufficient to cause hepatic steatosis and insulin resistance in lean rats [36]. Conversely, mice lacking GPAT1 are lean and exhibit diminished hepatic DAG and triglyceride content, especially in the context of high fat diet [37-39] or in an ob/ob genetic background [40]. Likewise, shRNA-mediated knockdown of GPAT1 in liver of ob/ob mice markedly reduced hepatic triglyceride content in just a few days [41]. The attenuation of hepatic steatosis was accompanied by improved hepatic insulin sensitivity in mice fed high fat diet [37]. Interestingly, the protection against hepatic steatosis in ob/ob mice did not result in improved insulin sensitivity [40], but the differences between the effects of GPAT1 knockout in the high fat diet and ob/ob models are unclear. It is likely that the inability to esterify fatty acids into nascent triglyceride and other lipids causes the hepatocyte to direct free fatty acids to an oxidative fate, since GPAT1 knockout mice exhibit strong elevations in fatty acid oxidation $[35,39]$.

GPAT4 is an ER-localized GPAT family member that also likely accounts for about $50 \%$ of total hepatic GPAT activity $[42,43]$. GPAT4 null mice are lean, exhibit reduced hepatic triglyceride content on a chow diet, and are protected from high fat diet-induced hepatic steatosis [44]. However, relatively little about the physiologic and metabolic functions of GPAT4 is known at this point.

4.2. Acylglycerol-3-Phosphate Acyltransferase. AGPAT enzymes (alternatively notated as LPA acyltransferases (LPAAT)) convert LPA to PA by acylating this phosphoglycerolipid intermediate. Myriad enzymes that can catalyze this reaction have been identified. Based on sequence homology, ten AGPAT family members have been proposed, but at least two of these (AGPAT6 and 8) are now known to likely be members of the GPAT family (GPAT3 and 4). Additionally, PNPLA3, which is strongly linked to hepatic steatosis in human populations, may also catalyze this enzymatic reaction [45], but PNPLA3 will be discussed below. Many members of this family of AGPAT enzymes have been incompletely characterized and a great deal of the research on this topic has been focused on AGPAT2, which is relevant to the liver and development of hepatic steatosis.

Biochemical analyses of AGPAT2 have suggested that this member of the AGPAT family may harbor the highest 
intrinsic AGPAT activity of all family members [46] and AGPAT2 is expressed in several metabolically important tissues. AGPAT2 knockout in mice or mutations in human subjects lead to severe congenital lipodystrophy (lack of adipose tissue) and hepatic steatosis that is likely secondary to the inability to appropriately store fatty acids in adipose tissue $[47,48]$. Hepatic AGPAT activity is reduced $90 \%$ in AGPAT2 knockout mice compared to WT controls despite increased expression of other AGPAT family mRNAs [47]. Given this marked decrement in hepatic AGPAT activity, the profound hepatic steatosis in these mice is somewhat surprising. It is possible that the residual AGPAT activity is sufficient for high rates of PA synthesis. Alternatively, marked activation of MGAT pathway (discussed below) in livers of these mice could suggest compensatory activation of another pathway for DAG and triglyceride synthesis [47]. The effects of liverspecific inactivation of AGPAT2 have, to our knowledge, not been performed to determine whether inhibition of this enzyme in hepatocytes could affect the development or progression of NAFLD.

4.3. Lipin Proteins. Lipin proteins are unique in this pathway as they are lipid phosphatases rather than acyltransferases and are also not integral membrane proteins. Lipin 1, lipin 2, and lipin 3 dephosphorylate PA to form DAG (PAP activity) $[33,49]$ and associate with the ER membranes transiently through a polybasic domain that binds to membraneembedded PA via electrostatic interactions [50]. Lipins are also unique in that they can translocate into the nucleus of the cell and directly regulate gene transcription [51]. All three lipin proteins are expressed to some extent in the liver $[52,53]$. Our present understanding is that both lipin 1 and lipin 2 encode significant hepatic PAP activity [53].

Lipin 1 is moderately expressed in normal liver, but its expression is strongly induced by several stimuli associated with increased PAP activity. For example prolonged fasting [51], glucocorticoid administration [51], and experimental ethanol feeding [54] are all associated with increased lipin 1 expression and PAP activity. Since lipin 1 is the lipin protein with the highest intrinsic PAP activity, this makes physiologic sense. Loss of lipin 1 in liver reduces hepatic PAP activity by $25-50 \%[49,52,53,55]$. Interestingly, mice constitutively deficient in lipin 1 (fld mice) exhibit lipodystrophy and marked hepatic steatosis similar to that exhibited by AGPAT2 $^{-/-}$mice. The capacity for triglyceride synthesis in mouse hepatocytes is not impaired by loss of lipin 1 [56] due to high expression of lipin 2 in hepatocytes [53]. However, mutations in the human gene encoding lipin 1 do not result in lipodystrophy and fatty liver but instead result in acute recurrent rhabdomyolysis [57-59].

Two recent studies have identified links between genetic variation in the lipin 1 gene and development of NAFLD in pediatric subjects $[60,61]$ and lipin 1 is induced in high fat diet fed or ob/ob mice [62]. Additionally, acute knockdown of lipin 1 may attenuate fatty liver and associated insulin resistance [62]. However, it should also be noted that other mouse studies found that lipin 1 expression was diminished in obesity-related NAFLD [56] and studies conducted in obese human subjects found that lipin 1 expression increased with marked weight loss when hepatic steatosis was resolved [63]. In addition, liver-specific lipin 1 knockout may actually exacerbate alcoholic liver disease [55]. Further work will be needed to clarify some of these discrepancies.

Lipin 2 is the most abundantly expressed lipin family protein in liver $[53,64]$ and knockdown of lipin 2 in liver markedly reduced hepatic PAP activity [53]. However, constitutive knockout of lipin 2 actually increases hepatic PAP likely due to increased lipin 1 abundance [65]. Lipin 2 protein abundance is controlled independently of the level of its RNA due to regulation of its rate of translation [53]. Indeed, in several models of hepatic steatosis, lipin 2 protein levels are increased without corresponding changes in lipin 2 mRNA levels [53]. Lipin 2 knockdown reduced insulin resistance and hepatic steatosis in high fat diet fed mice and lipin 2 overexpression was sufficient to impair insulin signaling [66]. Collectively, these data suggest that therapies to inhibit lipin 1 and lipin 2 may have value for treating NAFLD, but additional work is needed to investigate this further. Clarification is also required on whether inhibition of cytosolic and nuclear functions of lipin are both beneficial or whether one activity should be preferentially targeted.

4.4. Monoacylglycerol Acyltransferase. Like lipin proteins, the product of the enzymatic reaction catalyzed by MGAT proteins is DAG, but the substrate is monoacylglycerol (MAG) rather than PA (Figure 1). The human and mouse genomes each contain three MGAT family genes (Mogat1, 2, and 3), but mouse Mogat3 gene is a pseudogene and is not analogous to the human MOGAT3 [67]. The MGATs are important for dietary fat absorption by intestinal enterocytes and Mogat1 and Mogat 2 are most highly expressed in the gastrointestinal system [68-70]. Relatively little is known about the effects of MGATs in extraintestinal tissues. Recent work has suggested that human liver exhibits significant MGAT activity and the expression of MOGAT genes is markedly induced in human patients with NAFLD [68] as well as rodent models of obesity $[71,72]$ and lipodystrophy [47]. Moreover, marked weight loss led to downregulation of MOGAT2 and MOGAT3 in human liver biopsies [68]. Recent work has suggested that MOGAT genes are targets of the peroxisome proliferatoractivated receptor $\gamma$ [71], which is activated in liver in NAFLD and likely drives expression of MOGAT genes in this context.

Since the cause and effect relationship between Mogat expression and NAFLD was not clear from the human observational studies above, we and others have taken a loss of function approach to knockdown Mogat gene expression in experimentally tractable models. Lee and colleagues used a liver-specific shRNA against Mogatl delivered via adenovirus to inhibit its expression in high fat diet fed mice and found that just 5 days of Mogatl knockdown led to reversal of hepatic steatosis and correction of associated metabolic abnormalities [71]. We have used antisense oligonucleotides (ASO) to knockdown Mogatl and also found that glucose tolerance and insulin sensitivity were improved in diet-induced obese and ob/ob mice. However, we found no effect on hepatic triglyceride and have demonstrated that the ASO actually 
increased hepatic DAG content [72]. In follow-up studies, we have also found that liver injury on a diet that causes NASH was not corrected by Mogatl knockdown despite the insulin sensitization (unpublished observation). This suggests a disconnect between the ability of Mogatl inhibition to insulin sensitize and to correct these abnormalities. Our recent work has suggested that the human MOGAT1 mRNA transcript is subject to extensive alternative splicing and that very little full length coding transcript is actually present [68]. Nonetheless, the studies conducted in mice still argue that targeting MGAT activity in liver, possibly by modulating MGAT3, could have utility for treating NAFLD and hepatic insulin sensitivity.

Important roles for Mogat2 in metabolic homeostasis have also been identified. MOGAT2 expression was increased in human NAFLD patients compared to nonsteatotic controls and MOGAT2 expression declined after marked weight loss caused by gastric bypass surgery [68]. Yen and colleagues used Mogat 2 null mice to show that loss of this protein in a global manner prevented hepatic steatosis and weight gain in mice on a high fat diet [73]. It is likely that the bulk, but not all, of this phenotype is due to loss of Mogat2 in intestinal enterocytes [74]. Future work with liver-specific deletion or inhibition of Mogat2 is needed to clarify whether Mogat2 has liver autonomous effects on metabolism.

Mouse Mogat3 is a pseudogene [67]. The rat Mogat3 gene encodes a protein, but it is not analogous to human MGAT3, since the rodent gene was generated by duplication of Mogat2 while human MOGAT3 arose from duplication of the DGAT2 gene [67]. As a result, human MGAT3 exhibits both MGAT and DGAT activity [68]. Virtually nothing is known about rodent MGAT3. Human MOGAT3 is expressed in liver and hepatic MGAT activity is strongly correlated with hepatic MOGAT3 expression [68]. MOGAT3 expression is also induced in patients with NAFLD compared to nonsteatotic controls [68]. However, the lack of analogous MGAT3 activity in genetically tractable systems has made it difficult to examine the effects of modulating MGAT3 activity on hepatic steatosis.

4.5. Diacylglycerol Acyltransferase. The terminal step in triglyceride synthesis, using DAG produced from either PAP activity or MGAT activity, is catalyzed by DGAT1 and DGAT2. DGATs are well expressed in liver and have been targeted for gene deletion or knockdown by a number of studies. DGATs are integral membrane proteins of the ER and are therefore poised to direct the synthesis of triglyceride for lipidation of the core of nascent LD. Both DGAT1 and DGAT2 have been targeted by pharmaceutical companies as a potential treatment for obesity and related metabolic diseases, but no drug specifically targeting these enzymes has yet reached market.

DGAT1 knockout mice are viable, lean, and resist dietinduced obesity [75]. DGAT1 mice also exhibit reduced rates of triglyceride synthesis, but due to the existence of DGAT2, are able to synthesize triglyceride. Mice with global or liverspecific DGAT1 knockout were strongly protected from high fat diet-induced hepatic steatosis $[76,77]$. Furthermore, liverspecific gene knockout and ASO-mediated knockdown of
DGAT1 reduced liver triglyceride due to esterification of exogenous fatty acids [76]. However, another study found that ASO-mediated knockdown of DGAT1 in liver did not affect hepatic accumulation of triglyceride, even though hepatic DGAT activity was markedly reduced [78]. The lack of effect on hepatic triglyceride content was also observed in a second study that used ob/ob mice fed a methionine/cholinedeficient (MCD) diet [79]. DGAT1 inhibition did not affect insulin sensitivity in the high fat diet fed rats [78], but DGAT1 knockdown reduced hepatic fibrosis likely by reducing stellate cell activation and production of profibrotic factors in mice fed the MCD diet [79].

Hepatitis $\mathrm{C}$ virus (HCV) infection is also associated with development of hepatic steatosis. Interestingly, core protein components of HCV associate with LD and DGAT1 in hepatocytes and DGAT1 is required for HCV to traffic to LD [80]. DGAT1 is also required for the development of hepatic steatosis in response to HCV core proteins in mice and the steatosis associated with $\mathrm{HCV}$ infection may be due to inhibition of triglyceride turnover by HCV proteins [81]. Could DGAT1 inhibitors have value for inhibiting HCVmediated hepatic steatosis and viral replication? This intriguing idea for addressing an undertreated public health problem may have potential.

DGAT2 knockout mice die during the perinatal period due to lipid and skin barrier integrity abnormalities [82]. However, ASO-mediated knockdown has been used to assess the effects of DGAT2 inhibition on hepatic steatosis [78, 83]. These studies showed that DGAT2 knockdown reduced hepatic lipid accumulation and improved hepatic and whole body insulin sensitivity. The improvement in insulin sensitivity was correlated with a reduction in hepatic content of DAG, which activates PKC enzymes linked to insulin resistance, and a corresponding reduction in $\mathrm{PKC} \varepsilon$ activity [78]. Inhibition of DGAT2 in ob/ob mice fed an MCD diet reduced hepatic triglyceride content but exacerbated liver inflammation and injury [84], which contrasts the effects of DGAT1 inhibition [79] discussed above. One interpretation of these data is that appropriate storage of lipid in triglyceride is actually a protective mechanism and that interfering with this process at the wrong step could produce hepatic injury. Liverspecific overexpression of DGAT2 in transgenic mice led to an accumulation of DAG and TAG but, interestingly, did not affect insulin sensitivity [85]. Subsequent analyses of these mice suggested that hepatic insulin sensitivity was impaired [86], but the discrepant results between the two studies have not yet been explained.

\section{Lipid Droplet Proteins}

The lipid droplet was once considered an inert structure within the cell that served as a reservoir for neutral lipid storage. While it is true that LDs serve this purpose, we now know that the LD is also an organelle that plays important roles in regulating lipid storage, trafficking, and lipolysis. One of the major regulatory nodes controlling LD function is the coat of proteins that decorate the surface of lipid droplets. Knockout mouse models have provided strong evidence that 
these proteins are required for proper lipid storage and that LDP serve as important regulators of lipid hydrolysis. The current understanding of the roles that the two major families of lipid droplet proteins play in hepatic lipid homeostasis will be discussed.

5.1. Perilipin Family. Five proteins with strong sequence homology comprise the family of perilipin proteins (perilipin $1,2,3,4$, and 5 proteins) that are encoded by the five Plin genes [87]. Perilipin 1 was originally identified as an abundant phosphoprotein associated with the lipid fraction of adipocytes [88]. Immunofluorescent staining and other biochemical studies demonstrated that this protein coats lipid droplets and protects triglyceride from hydrolysis under basal conditions but is phosphorylated in response to cAMP signaling and subsequently serves to enhance lipolysis by allowing lipases to dock with the LD. In mouse studies, perilipin 1 protein is essentially undetectable in liver even in the context of hepatic steatosis [29]. However, immunofluorescent staining of human NAFLD liver sections has readily detected perilipin 1 coating LDs [89], suggesting an important species difference in sites of expression. Evidence has emerged that perilipin 1 may be a clinical marker of chronic hepatic steatosis that is increased depending upon the duration of NAFLD [90].

The other members of the perilipin family are expressed in mouse and human liver to varying degrees and depending upon the physiologic context. Perilipin 2 (also known as adipophilin or ADRP) has been shown to be induced in a number of models of hepatic steatosis $[29,89,91,92]$ due to increased expression of the gene encoding this protein as well as increased stability of the protein likely caused by the abundance of lipid. Indeed, the presence of exogenous lipid increases the protein half-life of several members of this protein family. Perilipin 2 knockout mice are protected from high fat diet-induced hepatic steatosis $[93,94]$ and intercross of perilipin 2 null mice into an ob/ob background abrogated hepatic steatosis in that model as well [95]. Acute inhibition of perilipin 2 expression by ASO also reduced hepatic steatosis and improved insulin sensitivity in diet-induced obese mice $[96,97]$.

Perilipin 3 is well expressed in mouse liver at baseline, but hepatic steatosis may have little effect on its protein abundance. On the other hand, perilipin 4 seems to be induced by high fat diet feeding [72]. However, the effects of perilipin 3 or perilipin 4 inhibition or knockout on hepatic steatosis have not been reported in the literature to date. Perilipin 5 is also induced in several models of fatty liver disease $[29,98]$. Altogether, the available data suggest a strong effect of inhibiting perilipin family protein expression of hepatic steatosis in a variety of mouse and rat models.

5.2. Cell Death-Inducing DFFA-Like Effector Family. Originally classified as regulators of cell death, CIDE family members have now been shown to regulate lipid metabolism via associations with lipid droplets to regulate their lipidation and size. Three members of this family exist in higher organisms (CIDEA, CIDEB, and CIDEC (Fsp27)).
CIDEA is associated with cytoplasmic LD [99] and is expressed at relatively low levels in liver normally. However, its expression is robustly induced by fatty liver in various rodent models $[29,100,101]$. CIDEA expression also correlates well with body mass index and hepatic steatosis in obese human subjects $[100,102]$ and its expression is regulated by the sterol-response element binding protein 1 [29], which is a transcription factor that is activated in fatty liver models. Knocking out or knocking down CIDEA in liver of dietinduced obese or ob/ob mice attenuated hepatic steatosis and led to accumulation of morphologically smaller lipid droplets in hepatocytes $[100,103]$.

Hepatic expression of CIDEB is normally very high and its abundance does not seem to be induced in experimental and human models of hepatic steatosis [29, 102]. However, CIDEB knockout mice are protected from diet-induced hepatic steatosis [104] and CIDEB seems to play an important role in very low density lipoprotein particle synthesis and lipidation [105-108]. CIDEB is associated with lipid droplets as well as the ER [105], which is consistent with its role in regulating triglyceride secretion by the liver. Other than the protective effects of CIDEB knockout on hepatic steatosis, little is known regarding the role of CIDEB in regulating liver lipid content in vivo.

The last member of this family, CIDEC or fat-specific protein 27 (Fsp27), is an LDP that was described as an adipocyte-specific gene induced by adipocyte differentiation [109]. Many genes in the adipogenic program are activated in fatty liver and the expression of CIDEC has been shown to be robustly induced in a variety of studies conducted in mouse [29, 110-112] and human [102] NAFLD. Moreover, overexpression of CIDEC in liver promoted, while CIDEC knockdown attenuated, hepatic steatosis in mouse studies [110], suggesting that CIDEC is both sufficient and necessary for development of NAFLD. However, another recent work on stellate cell activation has suggested that CIDEC may play a protective role in preventing hepatic fibrosis by reducing expression of factors required for fibrotic lesion formation [113]. It is not clear how these protective effects are mediated or whether inhibition of CIDEC would have negative or protective effects in other models of NASH.

\section{Triglyceride Hydrolysis Enzymes}

A number of lipases in the liver are involved in the turnover of hepatic cytosolic lipid droplets. For this review, we have chosen to focus on specific lipases linked to regulating of hepatic steatosis and lipid homeostasis.

6.1. Adipose Tissue Triglyceride Lipase. ATGL is a major hepatic triglyceride lipase. Genetic deficiency in ATGL leads to ectopic lipid accumulation, due to the inability to mobilize stored triglycerides, in a number of tissues including the liver [114]. The effects of liver-specific ATGL knockout or knockdown have also now been examined in several contexts. ATGL deficiency led to hepatic steatosis, but the majority of these papers have not detected hepatic insulin resistance, inflammation, or fibrosis [114-117]. However, one recent 
paper challenging ATGL knockout mice with MCD diet and LPS did detect increased inflammation [118]. Similarly, humans with ATGL mutations seem to be spared the usual consequences of ectopic lipid accumulation on insulin sensitivity [119]. Since much of the lipid in ATGL deficient mice and humans is trapped in the triglyceride pool, this may be additional evidence that triglyceride is not a lipid that causes insulin resistance or lipotoxicity. Conversely, overexpression of ATGL in liver ameliorates hepatic steatosis and promotes the disposal of fatty acids in oxidative mitochondrial metabolism [120]. This likely occurs because ATGL liberates fatty acid substrates that are directed to the mitochondrion for oxidation, but evidence also exists that ATGL activates $\operatorname{PPAR} \alpha$ [121], which is a critical transcriptional regulator of genes encoding fatty acid oxidation enzymes in liver [122].

6.2. Hormone Sensitive Lipase. Once considered the primary triglyceride hydrolase, HSL is now considered to be a primary DAG lipase. The phenotype of HSL knockout mice was an important driving force for this revelation since mice lacking HSL retained triglyceride hydrolase activity and exhibited a lean phenotype $[123,124]$. HSL deficient mice also exhibit increased hepatic insulin sensitivity $[125,126]$. Similar to ATGL, adenoviral-mediated overexpression of HSL reduced hepatic steatosis and enhanced rates of fatty acid oxidation [120].

6.3. Monoacylglycerol Lipase (MAGL). This protein functions to hydrolyze monoacylglycerol to glycerol and a free fatty acid in the final step of lipolytic degradation of triglyceride. MAGL global knockout exhibited a $40 \%$ reduction in hepatic MAGL activity but exhibited a marked accumulation of MAG in liver and had attenuated high fat diet-induced insulin resistance [127]. No information on the effects of MAGL deficiency on hepatic steatosis in the context of high fat diet-induced or other forms of obesity, to our knowledge, has been published. The importance of this enzyme, in addition to the regulating of glycerolipid hydrolysis, is that MAGL hydrolyzes species of MAG known as endocannabinoids, the most abundant endogenous ligands of cannabinoid receptors [128], which are known to regulate intermediary metabolism and may be involved in the insulin resistance of obesity. Further work is needed to connect the activity of the MAGL enzyme, endocannabinoid signaling, and the hepatic metabolic complications of obesity.

6.4. Patatin-Like Phospholipase Domain Containing 3. Recent work has shown that genetic variation in PNPLA3 is strongly associated with NAFLD in a variety of human populations [129]. In fact, a coding single nucleotide polymorphism (SNP) in PNPLA3 may be the single greatest genetic predictor of NAFLD and NASH susceptibility. The initial identification of the association between the PNPLA3 SNP and hepatic steatosis resulted from a genomewide association study across a number of ethnic populations with high (Hispanic) or low (African American) prevalence of hepatic steatosis [129]. A single amino acid substitution from isoleucine to methionine (I148M) was strongly associated with development of hepatic steatosis and the frequency of this allele was very high in Hispanics and low in African Americans. Subsequent studies have validated the link between I148M and hepatic steatosis prevalence and have suggested that this variant is also associated with increased risk of progression to NASH [130135]. PNPLA3 I148M has also been linked to increased risk of cirrhosis in hereditary hemochromatosis [135] and hepatocellular carcinoma [136]. The many pathologies associated with I148M make PNPLA3 a potentially appealing target for drug discovery.

Despite the wealth of studies demonstrating the link between PNPLA3 I148M and hepatic steatosis in human populations, there remains controversy regarding the molecular mechanisms whereby I148M drives hepatic steatosis. This is due to species differences in sites of expression and enzymatic activity between mice and man. Mice express relatively low levels of PNPLA3 in liver, while this gene is well expressed in human liver $[137,138]$ and because of their low hepatic PNPLA3 expression, studies conducted in PNPLA3 knockout mice have been inconclusive [139]. Based on homology, PNPLA3 is a member of the protein family that contains ATGL and other phospholipases and PNPLA3 has been shown to exhibit lipolytic activity [140]. However, PNPLA3 has also been convincingly shown to possess activity as an AGPAT/LPAAT [45]. The genetic variation linked to NAFLD incidence (I148M) has been shown experimentally to decrease lipolytic activity and increase AGPAT activity $[45,140,141]$. Hepatic overexpression of PNPLA3 I148M in transgenic mice increased both rates of TG synthesis and led to reduced rates of TG turnover, whereas overexpression of the I148I allele did not [141]. Thus, it is not clear how the single amino acid substitution is linked to development of NAFLD and it is possible that both enzymatic activities may contribute to the development of hepatic steatosis. Given the prevalence and phenotypic influence of I148M on the incidence and progression of NASH, pharmacologic targeting of PNPLA3 has obviously gained a great deal of interest in the past few years.

\section{Conclusions}

Given the central role that lipid accumulation plays in the etiology and pathology of NAFLD and NASH, targeting the enzymes that regulate steady state lipid levels is attractive for treating these and related metabolic disorders. However, a greater understanding of the pathogenic mechanisms and mediators that control the hepatic content of these lipids may be needed before intelligently designed therapeutics can be produced. For example, triglyceride accumulation may actually protect against inflammation and insulin resistance whereas other intermediates in these pathways can provoke these responses. Intervening at the wrong steps may actually exacerbate liver injury and we have little information regarding which steps should be targeted for chronic inhibition or activation. It is also not clear that specifically targeting one enzyme in these processes will have clinical efficacy. Compounds targeting these processes in a global manner might therefore have value. Early, but promising, clinical trials on 
obeticholic acid, a bile acid that activates the farnesoid X receptor and may promote fat catabolism, have suggested that this may be an efficacious way to alleviate hepatic steatosis and treat NASH [142]. Finally, very little is known regarding the role that stellate cell lipid metabolism plays in the development of NASH. Hepatic stellate cells, which are nonparenchymal cells of the liver, secrete collagen, the principal constituent of the fibrotic lesion. Although we now have reliable promoter-driven Cre to delete conditional alleles in a stellate cell-specific manner, the effects on stellate cell metabolism and hepatic injury and fibrosis have been little studied. This area still seems full of unanswered questions and progress towards developing new therapeutics has great potential to address an unmet medical need.

\section{Conflict of Interests}

The authors declare that there is no conflict of interests regarding the publication of this paper.

\section{Acknowledgments}

This work was supported by NIH Grant nos. R01 DK078187 and R42 AA021228. George G. Schweitzer is supported by NIH training Grant T32 HL007275.

\section{References}

[1] J. M. Clark and A. M. Diehl, "Nonalcoholic fatty liver disease: an underrecognized cause of cryptogenic cirrhosis," Journal of the American Medical Association, vol. 289, no. 22, pp. 3000-3004, 2003.

[2] J. M. Clark, F. L. Brancati, and A. M. Diehl, "Nonalcoholic fatty liver disease," Gastroenterology, vol. 122, no. 6, pp. 1649-1657, 2002.

[3] W. Youssef and A. J. McCullough, "Diabetes mellitus, obesity, and hepatic steatosis," Seminars in Gastrointestinal Disease, vol. 13, no. 1, pp. 17-30, 2002.

[4] W. I. Youssef and A. J. McCullough, "Steatohepatitis in obese individuals," Bailliere's Best Practice and Research in Clinical Gastroenterology, vol. 16, no. 5, pp. 733-747, 2002.

[5] J. D. Browning and J. D. Horton, "Molecular mediators of hepatic steatosis and liver injury," Journal of Clinical Investigation, vol. 114, no. 2, pp. 147-152, 2004.

[6] J. D. Browning, L. S. Szczepaniak, R. Dobbins et al., "Prevalence of hepatic steatosis in an urban population in the United States: impact of ethnicity," Hepatology, vol. 40, no. 6, pp. 1387-1395, 2004.

[7] K. Begriche, A. Igoudjil, D. Pessayre, and B. Fromenty, "Mitochondrial dysfunction in NASH: causes, consequences and possible means to prevent it," Mitochondrion, vol. 6, no. 1, pp. $1-38,2006$.

[8] I. R. Wanless and K. Shiota, "The pathogenesis of nonalcoholic steatohepatitis and other fatty liver diseases: a four-step model including the role of lipid release and hepatic venular obstruction in the progression to cirrhosis," Seminars in Liver Disease, vol. 24, no. 1, pp. 99-106, 2004.

[9] K. Te Sligte, I. Bourass, J. P. Sels, A. Driessen, R. W. Stockbrugger, and G. H. Koek, "Non-alcoholic steatohepatitis: review of a growing medical problem," European Journal of Internal Medicine, vol. 15, no. 1, pp. 10-21, 2004.

[10] C. Garcia-Ruiz, A. Colell, A. Morales, N. Kaplowitz, and J. C. Fernandez-Checa, "Role of oxidative stress generated from the mitochondrial electron transport chain and mitochondrial glutathione status in loss of mitochondrial function and activation of transcription factor nuclear factor- $\kappa \mathrm{B}$ : studies with isolated mitochondria and rat hepatocytes," Molecular Pharmacology, vol. 48, no. 5, pp. 825-834, 1995.

[11] B. Fromenty, M. A. Robin, A. Igoudjil, A. Mansouri, and D. Pessayre, "The ins and outs of mitochondrial dysfunction in NASH," Diabetes and Metabolism, vol. 30, no. 2, pp. 121-138, 2004.

[12] A. J. Sanyal, C. Campbell-Sargent, F. Mirshahi et al., "Nonalcoholic steatohepatitis: association of insulin resistance and mitochondrial abnormalities," Gastroenterology, vol. 120, no. 5, pp. 1183-1192, 2001.

[13] S. H. Caldwell, R. H. Swerdlow, E. M. Khan et al., "Mitochondrial abnormalities in non-alcoholic steatohepatitis," Journal of Hepatology, vol. 31, no. 3, pp. 430-434, 1999.

[14] S. Klein, B. Mittendorfer, J. C. Eagon et al., "Gastric bypass surgery improves metabolic and hepatic abnormalities associated with nonalcoholic fatty liver disease," Gastroenterology, vol. 130, no. 6, pp. 1564-1572, 2006.

[15] S. W. Coppack, D. L. Chinkes, J. M. Miles, B. W. Patterson, and S. Klein, "A multicompartmental model of in vivo adipose tissue glycerol kinetics and capillary permeability in lean and obese humans," Diabetes, vol. 54, no. 7, pp. 1934-1941, 2005.

[16] S. W. Coppack, J. F. Horowitz, D. S. Paramore, P. E. Cryer, H. D. Royal, and S. Klein, "Whole body, adipose tissue, and forearm norepinephrine kinetics in lean and obese women," American Journal of Physiology -Endocrinology and Metabolism, vol. 275, no. 5, pp. E830-E834, 1998.

[17] R. R. Townsend and S. Klein, "Lipolytic sensitivity and response to fasting in normotensive and hypertensive obese humans," Metabolism: Clinical and Experimental, vol. 46, no. 9, pp. 10801084, 1997.

[18] B. Mittendorfer, B. W. Patterson, S. Klein, and L. S. Sidossis, "VLDL-triglyceride kinetics during hyperglycemia-hyperinsulinemia: effects of sex and obesity," American Journal of Physiology_Endocrinology and Metabolism, vol. 284, no. 4, pp. E708-E715, 2003.

[19] B. Mittendorfer, B. W. Patterson, and S. Klein, "Effect of weight loss on VLDL-triglyceride and apoB-100 kinetics in women with abdominal obesity," American Journal of PhysiologyEndocrinology and Metabolism, vol. 284, no. 3, pp. E549-E556, 2003.

[20] I. Shimomura, M. Matsuda, R. E. Hammer, Y. Bashmakov, M. S. Brown, and J. L. Goldstein, "Decreased IRS-2 and increased SREBP-1c lead to mixed insulin resistance and sensitivity in livers of lipodystrophic and ob/ob mice," Molecular Cell, vol. 6, no. 1, pp. 77-86, 2000.

[21] Y. Shi and D. Cheng, "Beyond triglyceride synthesis: the dynamic functional roles of MGAT and DGAT enzymes in energy metabolism," American Journal of Physiology-Endocrinology and Metabolism, vol. 297, no. 1, pp. E10-E18, 2009.

[22] J. Cao, E. Hawkins, J. Brozinick et al., "A predominant role of Acyl-CoA:monoacylglycerol acyltransferase-2 in dietary fat absorption implicated by tissue distribution, subcellular localization, and up-regulation by high fat diet," Journal of Biological Chemistry, vol. 279, no. 18, pp. 18878-18886, 2004. 
[23] F. Wilfling, H. Wang, J. T. Haas et al., “Triacylglycerol synthesis enzymes mediate lipid droplet growth by relocalizing from the ER to lipid droplets," Developmental Cell, vol. 24, no. 4, pp. 384399, 2013.

[24] B. R. Bacon, M. J. Farahvash, C. G. Janney, and B. A. Neuschwander-Tetri, "Nonalcoholic steatohepatitis: an expanded clinical entity," Gastroenterology, vol. 107, no. 4, pp. 1103-1109, 1994.

[25] M. J. Contos, J. Choudhury, A. S. Mills, and A. J. Sanyal, "The histologic spectrum of nonalcoholic fatty liver disease," Clinics in Liver Disease, vol. 8, no. 3, pp. 481-500, 2004.

[26] B. Fromenty, A. Berson, and D. Pessayre, "Microvesicular steatosis and steatohepatitis: role of mitochondrial dysfunction and lipid peroxidation," Journal of Hepatology, Supplement, vol. 26, no. 1, pp. 13-22, 1997.

[27] E. Freneaux, G. Labbe, P. Letteron et al., "Inhibition of the mitochondrial oxidation of fatty acids by tetracycline in mice and in man: possible role in microvesicular steatosis induced by this antibiotic," Hepatology, vol. 8, no. 5, pp. 1056-1062, 1988.

[28] A. D. Burt, A. Mutton, and C. P. Day, "Diagnosis and interpretation of steatosis and steatohepatitis," Seminars in Diagnostic Pathology, vol. 15, no. 4, pp. 246-258, 1998.

[29] A. M. Hall, E. M. Brunt, Z. Chen et al., "Dynamic and differential regulation of proteins that coat lipid droplets in fatty liver dystrophic mice," Journal of Lipid Research, vol. 51, no. 3, pp. 554-563, 2010.

[30] C. Zhang, A. A. Wendel, M. R. Keogh, T. E. Harris, J. Chen, and R. A. Coleman, "Glycerolipid signals alter mTOR complex 2 (mTORC2) to diminish insulin signaling," Proceedings of the National Academy of Sciences of the United States of America, vol. 109, no. 5, pp. 1667-1672, 2012.

[31] O. Bezy, T. T. Tran, J. Pihlajamäki et al., "PKC $\delta$ regulates hepatic insulin sensitivity and hepatosteatosis in mice and humans," Journal of Clinical Investigation, vol. 121, no. 6, pp. 2504-2517, 2011.

[32] V. T. Samuel, Z.-X. Liu, A. Wang et al., "Inhibition of protein kinase $C \varepsilon$ prevents hepatic insulin resistance in nonalcoholic fatty liver disease," Journal of Clinical Investigation, vol. 117, no. 3, pp. 739-745, 2007.

[33] G.-S. Han, W.-I. Wu, and G. M. Carman, “The Saccharomyces cerevisiae lipin homolog is a $\mathrm{Mg}^{2+}$-dependent phosphatidate phosphatase enzyme," Journal of Biological Chemistry, vol. 281, no. 14, pp. 9210-9218, 2006.

[34] A. A. Wendel, T. M. Lewin, and R. A. Coleman, "Glycerol-3phosphate acyltransferases: rate limiting enzymes of triacylglycerol biosynthesis," Biochimica et Biophysica Acta-Molecular and Cell Biology of Lipids, vol. 1791, no. 6, pp. 501-506, 2009.

[35] A. A. Wendel, D. E. Cooper, O. R. Ilkayeva, D. M. Muoio, and R. A. Coleman, "Glycerol-3-phosphate acyltransferase (GPAT)-1, but not GPAT4, incorporates newly synthesized fatty acids into triacylglycerol and diminishes fatty acid oxidation," The Journal of Biological Chemistry, vol. 288, no. 38, pp. 27299-27306, 2013.

[36] C. A. Nagle, J. An, M. Shiota et al., "Hepatic overexpression of glycerol-sn-3-phosphate acyltransferase 1 in rats causes insulin resistance," Journal of Biological Chemistry, vol. 282, no. 20, pp. 14807-14815, 2007.

[37] S. Neschen, K. Morino, L. E. Hammond et al., "Prevention of hepatic steatosis and hepatic insulin resistance in mitochondrial acyl-CoA:glycerol-sn-3-phosphate acyltransferase 1 knockout mice," Cell Metabolism, vol. 2, no. 1, pp. 55-65, 2005.

[38] L. E. Hammond, P. A. Gallagher, S. Wang et al., "Mitochondrial glycerol-3-phosphate acyltransferase-deficient mice have reduced weight and liver triacylglycerol content and altered glycerolipid fatty acid composition," Molecular and Cellular Biology, vol. 22, no. 23, pp. 8204-8214, 2002.

[39] M. Yazdi, A. Ahnmark, L. William-Olsson et al., "The role of mitochondrial glycerol-3-phosphate acyltransferase-1 in regulating lipid and glucose homeostasis in high-fat diet fed mice," Biochemical and Biophysical Research Communications, vol. 369, no. 4, pp. 1065-1070, 2008.

[40] A. A. Wendel, L. O. Li, Y. Li, G. W. Cline, G. I. Shulman, and R. A. Coleman, "Glycerol-3-phosphate acyltransferase 1 deficiency in ob/ob mice diminishes hepatic steatosis but does not protect against insulin resistance or obesity," Diabetes, vol. 59, no. 6, pp. 1321-1329, 2010.

[41] H. Xu, D. Wilcox, P. Nguyen et al., "Hepatic knockdown of mitochondrial GPAT1 in ob/ob mice improves metabolic profile," Biochemical and Biophysical Research Communications, vol. 349, no. 1, pp. 439-448, 2006.

[42] R. E. Gimeno and J. Cao, "Mammalian glycerol-3-phosphate acyltransferases: new genes for an old activity," Journal of Lipid Research, vol. 49, no. 10, pp. 2079-2088, 2008.

[43] C. A. Nagle, L. Vergnes, H. Dejong et al., "Identification of a novel sn-glycerol-3-phosphate acyltransferase isoform, GPAT4, as the enzyme deficient in Agpat6-/- mice," Journal of Lipid Research, vol. 49, no. 4, pp. 823-831, 2008.

[44] L. Vergnes, A. P. Beigneux, R. Davis, S. M. Watkins, S. G. Young, and K. Reue, "Agpat6 deficiency causes subdermal lipodystrophy and resistance to obesity," Journal of Lipid Research, vol. 47, no. 4, pp. 745-754, 2006.

[45] M. Kumari, G. Schoiswohl, C. Chitraju et al., "Adiponutrin functions as a nutritionally regulated lysophosphatidic acid acyltransferase," Cell Metabolism, vol. 15, no. 5, pp. 691-702, 2012.

[46] D. W. Leung, "The structure and functions of human lysophosphatidic acid acyltransferases," Front Biosci, vol. 6, pp. D944D953, 2001.

[47] V. A. Cortés, D. E. Curtis, S. Sukumaran et al., "Molecular mechanisms of hepatic steatosis and insulin resistance in the AGPAT2-deficient mouse model of congenital generalized lipodystrophy," Cell Metabolism, vol. 9, no. 2, pp. 165-176, 2009.

[48] A. K. Agarwal, E. Arioglu, S. De Almeida et al., "AGPAT2 is mutated in congenital generalized lipodystrophy linked to chromosome 9q34," Nature Genetics, vol. 31, no. 1, pp. 21-23, 2002.

[49] J. Donkor, M. Sariahmetoglu, J. Dewald, D. N. Brindley, and $\mathrm{K}$. Reue, "Three mammalian lipins act as phosphatidate phosphatases with distinct tissue expression patterns," Journal of Biological Chemistry, vol. 282, no. 6, pp. 3450-3457, 2007.

[50] H. Ren, L. Federico, H. Huang et al., "A phosphatidic acid binding/nuclear localization motif determines lipin1 function in lipid metabolism and adipogenesis," Molecular Biology of the Cell, vol. 21, no. 18, pp. 3171-3181, 2010.

[51] B. N. Finck, M. C. Gropler, Z. Chen et al., "Lipin 1 is an inducible amplifier of the hepatic PGC- $1 \alpha / \mathrm{PPAR} \alpha$ regulatory pathway," Cell Metabolism, vol. 4, no. 3, pp. 199-210, 2006.

[52] T. E. Harris, T. A. Huffman, A. Chi et al., "Insulin controls subcellular localization and multisite phosphorylation of the phosphatidic acid phosphatase, lipin 1," Journal of Biological Chemistry, vol. 282, no. 1, pp. 277-286, 2007.

[53] M. C. Gropler, T. E. Harris, A. M. Hall et al., "Lipin 2 is a liver-enriched phosphatidate phosphohydrolase enzyme that is dynamically regulated by fasting andobesity in mice," Journal of Biological Chemistry, vol. 284, no. 11, pp. 6763-6772, 2009. 
[54] M. Hu, F. Wang, X. Li et al., "Regulation of hepatic lipin-1 by ethanol: role of AMP-activated protein kinase/sterol regulatory element-binding protein 1 signaling in mice," Hepatology, vol. 55, no. 2, pp. 437-446, 2012.

[55] M. Hu, H. Yin, M. S. Mitra et al., "Hepatic-specific lipin1 deficiency exacerbates experimental alcohol-induced steatohepatitis in mice," Hepatology, vol. 58, no. 6, pp. 1953-1963, 2013.

[56] Z. Chen, M. C. Gropler, J. Norris, J. C. Lawrence Jr., T. E. Harris, and B. N. Finck, "Alterations in hepatic metabolism in fld mice reveal a role for lipin 1 in regulating VLDL-triacylglyceride secretion," Arteriosclerosis, Thrombosis, and Vascular Biology, vol. 28, no. 10, pp. 1738-1744, 2008.

[57] A. Zeharia, A. Shaag, R. H. Houtkooper et al., "Mutations in LPIN1 cause recurrent acute myoglobinuria in childhood," American Journal of Human Genetics, vol. 83, no. 4, pp. 489494, 2008.

[58] C. Michot, L. Hubert, M. Brivet et al., "LPIN1 gene mutations: a major cause of severe rhabdomyolysis in early childhood," Human Mutation, vol. 31, no. 7, pp. E1564-E1573, 2010.

[59] C. Michot, L. Hubert, N. B. Romero et al., "Study of LPIN1, LPIN2 and LPIN3 in rhabdomyolysis and exercise-induced myalgia," Journal of Inherited Metabolic Disease, vol. 35, no. 6, pp. 1119-1128, 2012.

[60] V. Nobili, B. Donati, N. Panera et al., "A Four-polymorphisms risk score predicts steatohepatitis in children with nonalcoholic fatty liverdisease," Journal of Pediatric Gastroenterology and Nutrition. In press.

[61] L. Valenti, B. M. Motta, A. Alisi et al., "LPIN1 rs13412852 polymorphism in pediatric nonalcoholic fatty liver disease," Journal of Pediatric Gastroenterology and Nutrition, vol. 54, no. 5, pp. 588-593, 2012.

[62] D. Ryu, K.-J. Oh, H.-Y. Jo et al., “TORC2 regulates hepatic insulin signaling via a mammalian phosphatidic acid phosphatase, LIPIN1," Cell Metabolism, vol. 9, no. 3, pp. 240-251, 2009.

[63] M. A. Croce, J. C. Eagon, L. L. LaRiviere, K. M. Korenblat, S. Klein, and B. N. Finck, "Hepatic lipin $1 \beta$ expression is diminished in insulin-resistant obese subjects and is reactivated by marked weight loss," Diabetes, vol. 56, no. 9, pp. 2395-2399, 2007.

[64] J. Donkor, P. Zhang, S. Wong et al., "A conserved serine residue is required for the phosphatidate phosphatase activity but not the transcriptional coactivator functions of lipin-1 and lipin2," Journal of Biological Chemistry, vol. 284, no. 43, pp. 2996829978, 2009.

[65] J. R. Dwyer, J. Donkor, P. Zhang et al., "Mouse lipin-1 and lipin-2 cooperate to maintain glycerolipid homeostasis in liver and aging cerebellum," Proceedings of the National Academy of Sciences of the United States of America, vol. 109, no. 37, pp. E2486-E2495, 2012.

[66] D. Ryu, W.-Y. Seo, Y.-S. Yoon et al., "Endoplasmic reticulum stress promotes LIPIN2-dependent hepatic insulin resistance," Diabetes, vol. 60, no. 4, pp. 1072-1081, 2011.

[67] Y. G. Yue, Y. Q. Chen, Y. Zhang et al., "The acyl coenzymeA:monoacylglycerol acyltransferase 3 (MGAT3) gene is a pseudogene in mice but encodes a functional enzyme in rats," Lipids, vol. 46, no. 6, pp. 513-520, 2011.

[68] A. M. Hall, K. Kou, Z. Chen et al., "Evidence for regulated monoacylglycerol acyltransferase expression and activity in human liver," Journal of Lipid Research, vol. 53, no. 5, pp. 990999, 2012.
[69] C.-L. E. Yen, S. J. Stone, S. Cases, P. Zhou, and R. V. Farese Jr., "Identification of a gene encoding MGAT1, a monoacylglycerol acyltransferase," Proceedings of the National Academy of Sciences of the United States of America, vol. 99, no. 13, pp. 8512-8517, 2002.

[70] C.-L. E. Yen and R. V. Farese Jr., "MGAT2, a monoacylglycerol acyltransferase expressed in the small intestine," Journal of Biological Chemistry, vol. 278, no. 20, pp. 18532-18537, 2003.

[71] Y. J. Lee, E. H. Ko, J. E. Kim et al., "Nuclear receptor PPARgamma-regulated monoacylglycerol O-acyltransferase 1 (MGAT1) expression is responsible for the lipid accumulation in diet-induced hepatic steatosis," Proceedings of the National Academy of Sciences of the United States of America, vol. 109, no. 34, pp. 13656-13661, 2012.

[72] A. M. Hall, N. Soufi, K. T. Chambers et al., "Abrogating monoacylglycerol acyltransferase activity in liver improves glucose tolerance and hepatic insulin signaling in obese mice," Diabetes, 2014.

[73] C.-L. E. Yen, M.-L. Cheong, C. Grueter et al., "Deficiency of the intestinal enzyme acyl CoA:monoacylglycerol acyltransferase2 protects mice from metabolic disorders induced by high-fat feeding," Nature Medicine, vol. 15, no. 4, pp. 442-446, 2009.

[74] Y. Gao, D. W. Nelson, T. Banh, M. I. Yen, and C. L. Yen, "Intestine-specific expression of MOGAT2 partially restores metabolic efficiency in Mogat2-deficient mice," The Journal of Lipid Research, vol. 54, no. 6, pp. 1644-1652, 2013.

[75] S. J. Smith, S. Cases, D. R. Jensen et al., "Obesity resistance and multiple mechanisms of triglyceride synthesis in mice lacking Dgat," Nature Genetics, vol. 25, no. 1, pp. 87-90, 2000.

[76] C. J. Villanueva, M. Monetti, M. Shih et al., "Specific role for acyl CoA:diacylglycerol acyltransferase 1 (Dgat1) in hepatic steatosis due to exogenous fatty acids," Hepatology, vol. 50, no. 2, pp. 434442, 2009.

[77] H. C. Chen, S. J. Smith, Z. Ladha et al., "Increased insulin and leptin sensitivity in mice lacking acyl CoA:diacylglycerol acyltransferase 1," Journal of Clinical Investigation, vol. 109, no. 8, pp. 1049-1055, 2002.

[78] S. C. Cheol, D. B. Savage, A. Kulkarni et al., "Suppression of diacylglycerol acyltransferase-2 (DGAT2), but not DGAT1, with antisense oligonucleotides reverses diet-induced hepatic steatosis and insulin resistance," Journal of Biological Chemistry, vol. 282, no. 31, pp. 22678-22688, 2007.

[79] K. Yamaguchi, L. Yang, S. McCall et al., "Diacylglycerol acyltranferase 1 anti-sense oligonucleotides reduce hepatic fibrosis in mice with nonalcoholic steatohepatitis," Hepatology, vol. 47, no. 2, pp. 625-635, 2008.

[80] E. Herker, C. Harris, C. Hernandez et al., "Efficient hepatitis C virus particle formation requires diacylglycerol acyltransferase1," Nature Medicine, vol. 16, no. 11, pp. 1295-1298, 2010.

[81] C. Harris, E. Herker, R. V. Farese Jr., and M. Ott, "Hepatitis $\mathrm{C}$ virus core protein decreases lipid droplet turnover: a mechanism for core-induced steatosis," Journal of Biological Chemistry, vol. 286, no. 49, pp. 42615-42625, 2011.

[82] S. J. Stone, H. M. Myers, S. M. Watkins et al., "Lipopenia and skin barrier abnormalities in DGAT2-deficient mice," Journal of Biological Chemistry, vol. 279, no. 12, pp. 11767-11776, 2004.

[83] X. X. Yu, S. F. Murray, S. K. Pandey et al., "Antisense oligonucleotide reduction of DGAT2 expression improves hepatic steatosis and hyperlipidemia in obese mice," Hepatology, vol. 42, no. 2, pp. 362-371, 2005. 
[84] K. Yamaguchi, L. Yang, S. McCall et al., "Inhibiting triglyceride synthesis improves hepatic steatosis but exacerbates liver damage and fibrosis in obese mice with nonalcoholic steatohepatitis," Hepatology, vol. 45, no. 6, pp. 1366-1374, 2007.

[85] M. Monetti, M. C. Levin, M. J. Watt et al., "Dissociation of hepatic steatosis and insulin resistance in mice overexpressing dgat in the liver," Cell Metabolism, vol. 6, no. 1, pp. 69-78, 2007.

[86] F. R. Jornayvaz, A. L. Birkenfeld, M. J. Jurczak et al., "Hepatic insulin resistance in mice with hepatic overexpression of diacylglycerol acyltransferase 2," Proceedings of the National Academy of Sciences of the United States of America, vol. 108, no. 14, pp. 5748-5752, 2011.

[87] A. R. Kimmel, D. L. Brasaemle, M. McAndrews-Hill, C. Sztalryd, and C. Londos, "Adoption of PERILIPIN as a unifying nomenclature for the mammalian PAT-family of intracellular lipid storage droplet proteins," Journal of Lipid Research, vol. 51, no. 3, pp. 468-471, 2010.

[88] A. S. Greenberg, J. J. Egan, S. A. Wek, N. B. Garty, E. J. Blanchette-Mackie, and C. Londos, "Perilipin, a major hormonally regulated adipocyte-specific phosphoprotein associated with the periphery of lipid storage droplets," Journal of Biological Chemistry, vol. 266, no. 17, pp. 11341-11346, 1991.

[89] H. Fujii, Y. Ikura, J. Arimoto et al., "Expression of perilipin and adipophilin in nonalcoholic fatty liver disease; relevance to oxidative injury and hepatocyte ballooning," Journal of Atherosclerosis and Thrombosis, vol. 16, no. 6, pp. 893-901, 2009.

[90] L. M. Pawella, M. Hashani, E. Eiteneuer et al., "Perilipin discerns chronic from acute hepatocellular steatosis," Journal of Hepatology, vol. 60, no. 3, pp. 633-642, 2013.

[91] H. W. Heid, R. Moll, I. Schwetlick, H.-R. Rackwitz, and T. W. Keenan, "Adipophilin is a specific marker of lipid accumulation in diverse cell types and diseases," Cell and Tissue Research, vol. 294, no. 2, pp. 309-321, 1998.

[92] W. Motomura, M. Inoue, T. Ohtake et al., "Up-regulation of ADRP in fatty liver in human and liver steatosis in mice fed with high fat diet," Biochemical and Biophysical Research Communications, vol. 340, no. 4, pp. 1111-1118, 2006.

[93] B. H.-J. Chang, L. Li, A. Paul et al., "Protection against fatty liver but normal adipogenesis in mice lacking adipose differentiation-related protein," Molecular and Cellular Biology, vol. 26, no. 3, pp. 1063-1076, 2006.

[94] J. L. McManaman, E. S. Bales, D. J. Orlicky et al., "Perilipin-2null mice are protected against diet-induced obesity, adipose inflammation, and fatty liver disease," The Journal of Lipid Research, vol. 54, no. 5, pp. 1346-1359, 2013.

[95] B. H.-J. Chang, L. Li, P. Saha, and L. Chan, "Absence of adipose differentiation related protein upregulates hepatic VLDL secretion, relieves hepatosteatosis, and improves whole body insulin resistance in leptin-deficient mice," Journal of Lipid Research, vol. 51, no. 8, pp. 2132-2142, 2010.

[96] Y. Imai, S. Boyle, G. M. Varela et al., "Effects of perilipin 2 antisense oligonucleotide treatment on hepatic lipid metabolism and gene expression," Physiological Genomics, vol. 44, no. 22, pp. 1125-1131, 2012.

[97] G. M. Varela, D. A. Antwi, R. Dhir et al., "Inhibition of ADRP prevents diet-induced insulin resistance," American Journal of Physiology_Gastrointestinal and Liver Physiology, vol. 295, no. 3, pp. G621-G628, 2008.

[98] H. Li, Y. Song, L. J. Zhang et al., "LSDP5 enhances triglyceride storage in hepatocytes by influencing lipolysis and fatty acid beta-oxidation of lipid droplets," PLOS ONE, vol. 7, no. 6, Article ID e36712, 2012.
[99] V. Puri, S. Ranjit, S. Konda et al., "Cidea is associated with lipid droplets and insulin sensitivity in humans," Proceedings of the National Academy of Sciences of the United States of America, vol. 105, no. 22, pp. 7833-7838, 2008.

[100] L. Zhou, L. Xu, J. Ye et al., "Cidea promotes hepatic steatosis by sensing dietary fatty acids," Hepatology, vol. 56, no. 1, pp. 95-107, 2012.

[101] Y. Jinno, M. Nakakuki, A. Sato et al., "Cide-a and Cide-c are induced in the progression of hepatic steatosis and inhibited by eicosapentaenoic acid," Prostaglandins Leukotrienes and Essential Fatty Acids, vol. 83, no. 2, pp. 75-81, 2010.

[102] A. M. Hall, E. M. Brunt, S. Klein, and B. N. Finck, "Hepatic expression of cell death-inducing DFFA-like effector C in obese subjects is reduced by marked weight loss," Obesity, vol. 18, no. 2, pp. 417-419, 2010.

[103] Z. Zhou, S. Y. Toh, Z. Chen et al., "Cidea-deficient mice have lean phenotype and are resistant to obesity," Nature Genetics, vol. 35, no. 1, pp. 49-56, 2003.

[104] J. Z. Li, J. Ye, B. Xue et al., "Cideb regulates diet-induced obesity, liver steatosis, and insulin sensitivity by controlling lipogenesis and fatty acid oxidation," Diabetes, vol. 56, no. 10, pp. 2523-2532, 2007.

[105] J. Ye, J. Z. Li, Y. Liu et al., "Cideb, an ER- and lipid dropletassociated protein, mediates vldl lipidation and maturation by interacting with apolipoprotein B," Cell Metabolism, vol. 9, no. 2, pp. 177-190, 2009.

[106] Z. Chen, J. Y. Norris, and B. N. Finck, "Peroxisome proliferatoractivated receptor- $\gamma$ coactivator- $1 \alpha$ (PGC- $1 \alpha$ ) stimulates VLDL assembly through activation of cell death-inducing DFFA-like effector B (CideB)," Journal of Biological Chemistry, vol. 285, no. 34, pp. 25996-26004, 2010.

[107] S. Tiwari, S. Siddiqi, and S. A. Siddiqi, "CideB protein is required for the biogenesis of very low density lipoprotein (VLDL) transport vesicle," The Journal of Biological Chemistry, vol. 288, no. 7, pp. 5157-5165, 2013.

[108] X. Li, J. Ye, L. Zhou et al., "Opposing roles of cell death-inducing DFF45-like effector B and perilipin 2 in controlling hepatic VLDL lipidation," The Journal of Lipid Research, vol. 53, no. 9, pp. 1877-1889, 2012.

[109] U. Danesch, W. Hoeck, and G. M. Ringold, "Cloning and transcriptional regulation of a novel adipocyte-specific gene, FSP27. CAAT-enhancer-binding protein (C/EBP) and C/EBP-like proteins interact with sequences required for differentiationdependent expression," Journal of Biological Chemistry, vol. 267, no. 10, pp. 7185-7193, 1992.

[110] K. Matsusue, T. Kusakabe, T. Noguchi et al., "Hepatic steatosis in leptin-deficient mice is promoted by the PPAR $\gamma$ target gene Fsp27," Cell Metabolism, vol. 7, no. 4, pp. 302-311, 2008.

[111] S. Yu, K. Matsusue, P. Kashireddy et al., "Adipocyte-specific gene expression and adipogenic steatosis in the mouse liver due to peroxisome proliferator-activated receptor $\gamma 1$ (PPAR $\gamma 1$ ) overexpression," Journal of Biological Chemistry, vol. 278, no. 1, pp. 498-505, 2003.

[112] N. Guillén, M. A. Navarro, C. Arnal et al., "Microarray analysis of hepatic gene expression identifies new genes involved in steatotic liver," Physiological Genomics, vol. 37, no. 3, pp. 187-198, 2009.

[113] F. Yu, L. Su, S. Ji et al., "Inhibition of hepatic stellate cell activation and liver fibrosis by fat-specific protein 27," Molecular and Cellular Biochemistry, vol. 369, no. 1-2, pp. 35-43, 2012.

[114] A. J. Hoy, C. R. Bruce, S. M. Turpin, A. J. Morris, M. A. Febbraio, and M. J. Watt, "Adipose triglyceride lipase-null mice 
are resistant to high-fat diet-induced insulin resistance despite reduced energy expenditure and ectopic lipid accumulation," Endocrinology, vol. 152, no. 1, pp. 48-58, 2011.

[115] J. W. Wu, S. P. Wang, F. Alvarez et al., "Deficiency of liver adipose triglyceride lipase in mice causes progressive hepatic steatosis," Hepatology, vol. 54, no. 1, pp. 122-132, 2011.

[116] S. M. Turpin, A. J. Hoy, R. D. Brown et al., "Adipose triacylglycerol lipase is a major regulator of hepatic lipid metabolism but not insulin sensitivity in mice," Diabetologia, vol. 54, no. 1, pp. 146-156, 2011.

[117] K. T. Ong, M. T. Mashek, S. Y. Bu, and D. G. Mashek, "Hepatic ATGL knockdown uncouples glucose intolerance from liver TAG accumulation," The FASEB Journal, vol. 27, no. 1, pp. 313321, 2013.

[118] P. Jha, T. Claudel, A. Baghdasaryan et al., "Role of adipose triglyceride lipase (PNPLA2) in protection from hepatic inflammation in mouse models of steatohepatitis and endotoxemia," Hepatology, vol. 59, no. 3, pp. 858-869, 2014.

[119] A. Natali, A. Gastaldelli, S. Camastra et al., "Metabolic consequences of adipose triglyceride lipase deficiency in humans: an in vivo study in patients with neutral lipid storage disease with myopathy," The Journal of Clinical Endocrinology and Metabolism, vol. 98, no. 9, pp. E1540-E1548, 2013.

[120] B. N. Reid, G. P. Ables, O. A. Otlivanchik et al., "Hepatic overexpression of hormone-sensitive lipase and adipose triglyceride lipase promotes fatty acid oxidation, stimulates direct release of free fatty acids, and ameliorates steatosis," Journal of Biological Chemistry, vol. 283, no. 19, pp. 13087-13099, 2008.

[121] K. T. Ong, M. T. Mashek, S. Y. Bu, A. S. Greenberg, and D. G. Mashek, "Adipose triglyceride lipase is a major hepatic lipase that regulates triacylglycerol turnover and fatty acid signaling and partitioning," Hepatology, vol. 53, no. 1, pp. 116-126, 2011.

[122] T. C. Leone, C. J. Weinheimer, and D. P. Kelly, "A critical role for the peroxisome proliferator-activated receptor $\alpha$ (PPAR $\alpha)$ in the cellular fasting response: the PPAR $\alpha$-null mouse as a model of fatty acid oxidation disorders," Proceedings of the National Academy of Sciences of the United States of America, vol. 96, no. 13, pp. 7473-7478, 1999.

[123] K. Harada, W.-J. Shen, S. Patel et al., "Resistance to high-fat diet-induced obesity and altered expression of adipose-specific genes in HSL-deficient mice," American Journal of PhysiologyEndocrinology and Metabolism, vol. 285, no. 6, pp. E1182-E1195, 2003.

[124] S. J. Yeaman, "Hormone-sensitive lipase-new roles for an old enzyme," Biochemical Journal, vol. 379, no. 1, pp. 11-22, 2004.

[125] S.-Y. Park, H.-J. Kim, S. Wang et al., "Hormone-sensitive lipase knockout mice have increased hepatic insulin sensitivity and are protected from short-term diet-induced insulin resistance in skeletal muscle and heart," American Journal of PhysiologyEndocrinology and Metabolism, vol. 289, no. 1, pp. E30-E39, 2005.

[126] P. J. Voshol, G. Haemmerle, D. M. Ouwens et al., "Increased hepatic insulin sensitivity together with decreased hepatic triglyceride stores in hormone-sensitive lipase-deficient mice," Endocrinology, vol. 144, no. 8, pp. 3456-3462, 2003.

[127] U. Taschler, F. P. W. Radner, C. Heier et al., "Monoglyceride lipase deficiency in mice impairs lipolysis and attenuates dietinduced insulin resistance," Journal of Biological Chemistry, vol. 286, no. 20, pp. 17467-17477, 2011.

[128] Z. Cao, M. M. Mulvihill, P. Mukhopadhyay et al., "Monoacylglycerol lipase controls endocannabinoid and eicosanoid signaling and hepatic injury in mice," Gastroenterology, vol. 144, no. 4, pp. 808.e15-817.e15, 2013.

[129] S. Romeo, J. Kozlitina, C. Xing et al., "Genetic variation in PNPLA3 confers susceptibility to nonalcoholic fatty liver disease," Nature Genetics, vol. 40, no. 12, pp. 1461-1465, 2008.

[130] V. Nobili, G. Bedogni, B. Donati, A. Alisi, and L. Valenti, “The I148M variant of PNPLA3 reduces the response to docosahexaenoic acid in children with non-alcoholic fatty liver disease," Journal of Medicinal Food, vol. 16, no. 10, pp. 957-960, 2013.

[131] Y. Rotman, C. Koh, J. M. Zmuda, D. E. Kleiner, and T. J. Liang, "The association of genetic variability in patatin-like phospholipase domain-containing protein 3 (PNPLA3) with histological severity of nonalcoholic fatty liver disease," Hepatology, vol. 52, no. 3, pp. 894-903, 2010.

[132] S. Sookoian, G. O. Castaño, A. L. Burgueño, T. F. Gianotti, M. S. Rosselli, and C. J. Pirola, "A nonsynonymous gene variant in the adiponutrin gene is associated with nonalcoholic fatty liver disease severity," Journal of Lipid Research, vol. 50, no. 10, pp. 2111-2116, 2009.

[133] S. Sookoian and C. J. Pirola, "Meta-analysis of the influence of I148M variant of patatin-like phospholipase domain containing 3 gene (PNPLA3) on the susceptibility and histological severity of nonalcoholic fatty liver disease," Hepatology, vol. 53, no. 6, pp. 1883-1894, 2011.

[134] L. Valenti, A. Al-Serri, A. K. Daly et al., "Homozygosity for the patatin-like phospholipase-3/adiponutrin i148m polymorphism influences liver fibrosis in patients with nonalcoholic fatty liver disease," Hepatology, vol. 51, no. 4, pp. 1209-1217, 2010.

[135] L. Valenti, P. Dongiovanni, S. Ginanni Corradini, M. A. Burza, and S. Romeo, "PNPLA3 I148M variant and hepatocellular carcinoma: a common genetic variant for a rare disease," Digestive and Liver Disease, vol. 45, no. 8, pp. 619-624, 2013.

[136] L. Valenti, P. Maggioni, A. Piperno et al., "Patatin-like phospholipase domain containing-3 gene I148M polymorphism, steatosis, and liver damage in hereditary hemochromatosis," World Journal of Gastroenterology, vol. 18, no. 22, pp. 2813-2820, 2012.

[137] Y. Huang, S. He, J. Z. Li et al., "A feed-forward loop amplifies nutritional regulation of PNPLA3," Proceedings of the National Academy of Sciences of the United States of America, vol. 107, no. 17, pp. 7892-7897, 2010.

[138] M. Hoekstra, Z. Li, J. K. Kruijt, M. V. Eck, T. J. C. V. Berkel, and J. Kuiper, "The expression level of non-alcoholic fatty liver disease-related gene PNPLA3 in hepatocytes is highly influenced by hepatic lipid status," Journal of Hepatology, vol. 52, no. 2, pp. 244-251, 2010.

[139] W. Chen, B. Chang, L. Li, and L. Chan, "Patatin-like phospholipase domain-containing 3/adiponutrin deficiency in mice is not associated with fatty liver disease," Hepatology, vol. 52, no. 3, pp. 1134-1142, 2010.

[140] Y. Huang, J. C. Cohen, and H. H. Hobbs, "Expression and characterization of a PNPLA3 protein isoform (I148M) associated with nonalcoholic fatty liver disease," Journal of Biological Chemistry, vol. 286, no. 43, pp. 37085-37093, 2011.

[141] J. Z. Li, Y. Huang, R. Karaman et al., "Chronic overexpression of PNPLA3I148M in mouse liver causes hepatic steatosis," The Journal of Clinical Investigation, vol. 122, no. 11, pp. 4130-4144, 2012.

[142] S. Mudaliar, R. R. Henry, A. J. Sanyal et al., "Efficacy and safety of the farnesoid $\mathrm{X}$ receptor agonist obeticholic acid in patients with type 2 diabetes and nonalcoholic fatty liver disease," Gastroenterology, vol. 145, no. 3, pp. 574.e1-582.e1, 2013. 
[143] M. Péterfy, J. Phan, P. Xu, and K. Reue, "Lipodystrophy in the fld mouse results from mutation of a new gene encoding a nuclear protein, lipin," Nature Genetics, vol. 27, no. 1, pp. 121-124, 2001.

[144] K. Reue, P. Xu, X.-P. Wang, and B. G. Slavin, "Adipose tissue deficiency, glucose intolerance, and increased atherosclerosis result from mutation in the mouse fatty liver dystrophy (fld) gene," Journal of Lipid Research, vol. 41, no. 7, pp. 1067-1076, 2000.

[145] L. S. Csaki, J. R. Dwyer, X. Li et al., "Lipin-1 and lipin-3 together determine adiposity in vivo," Molecular Metabolism, vol. 3, no. 2, pp. 145-154, 2014. 


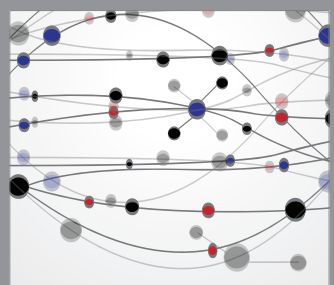

The Scientific World Journal
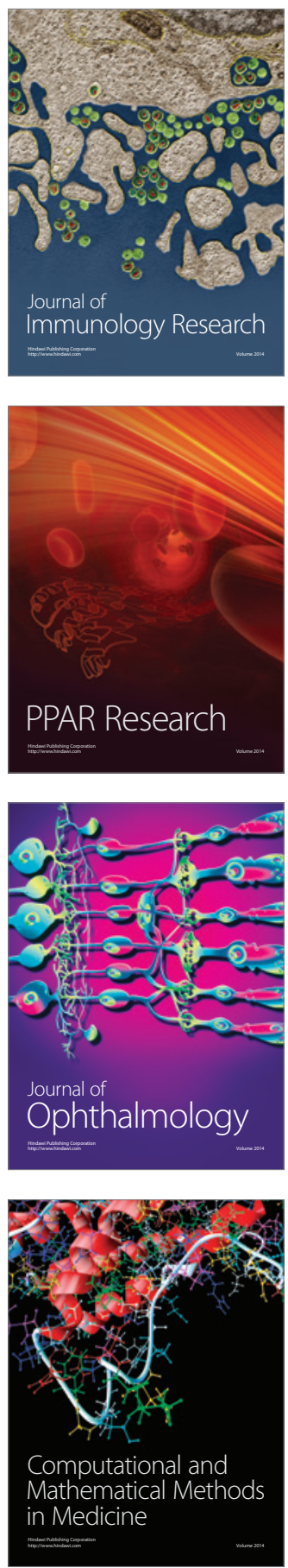

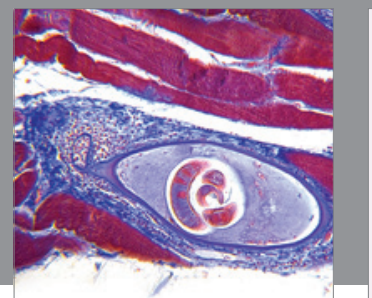

Gastroenterology

Research and Practice
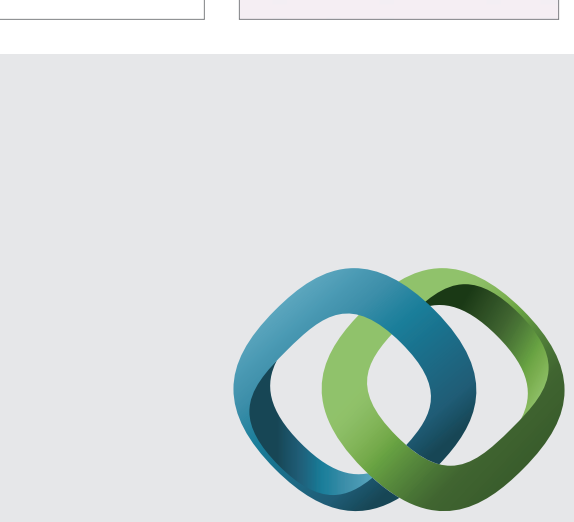

\section{Hindawi}

Submit your manuscripts at

http://www.hindawi.com
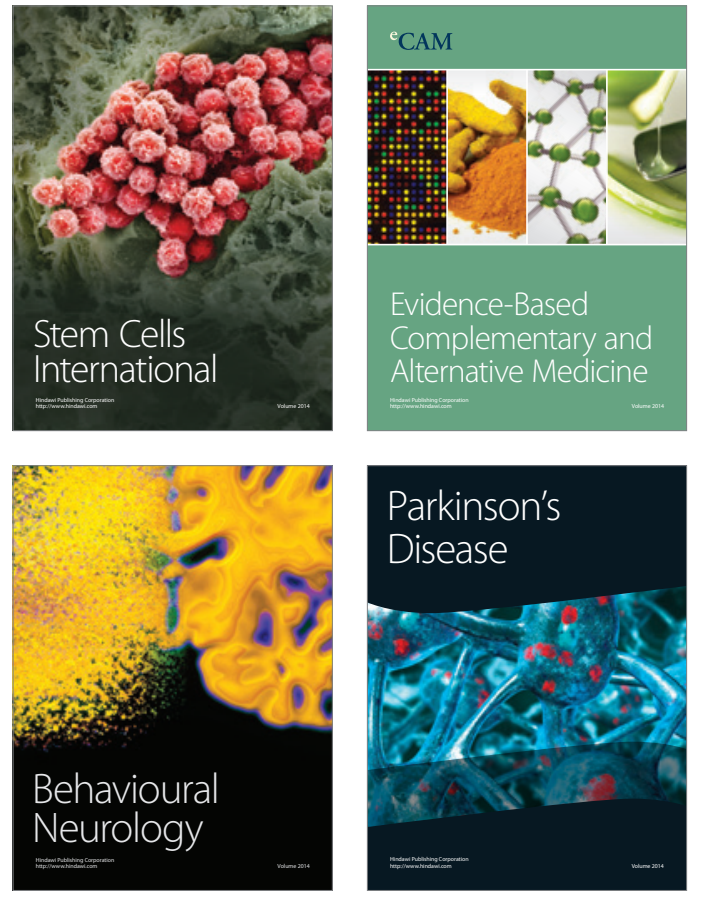
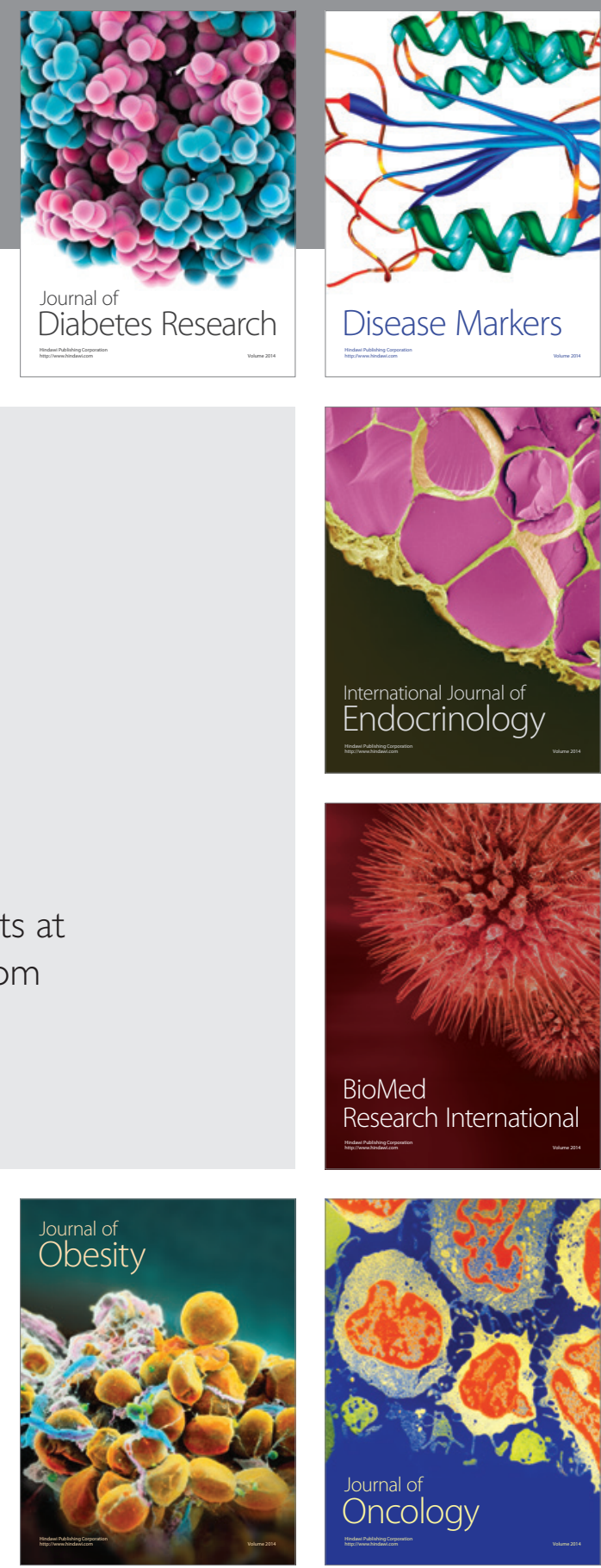

Disease Markers
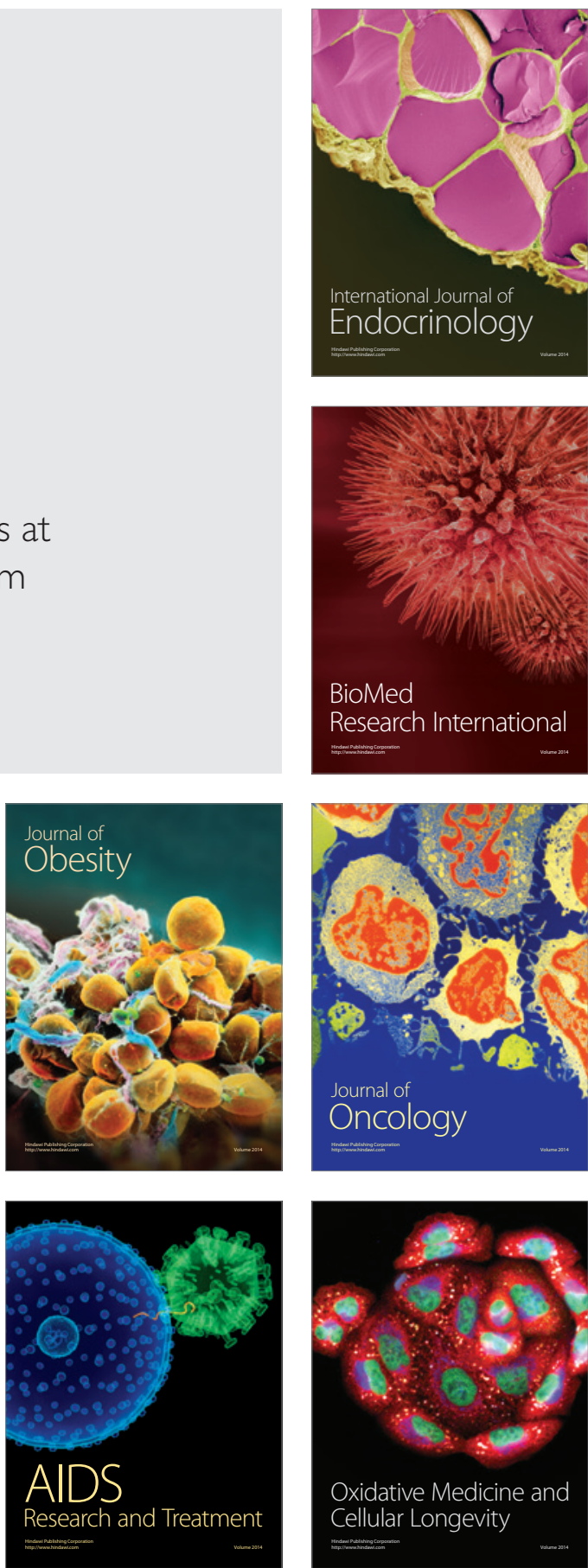